\title{
Prevention of Neurological Deterioration before Admission to a Spinal Cord Injury Unit
}

\author{
Joseph Toscano, MB, BS, MD(Melb)
}

Honorary Clinical Assistant, Department of Surgery, Austin Hospital, Melbourne, Australia.

\section{Summary \\ Thirty-two of 123 patients admitted to the Victorian Spinal Injuries Unit, Austin Hospital, during the period 1st March 1983 to 28th December, 1984 sustained major neurological deterioration from the time of injury to the time the patient was admitted to the Unit. The key to the prevention of major neurological deterioration in patients who have only vertebral column damage and in patients who have partial neurological dysfunction is a theoretical and practical understanding of the spinal column and cord. Suspicion about the possibility of spinal cord injury, followed by appropriate handling and immobilisation of these patients by treating personnel as soon as possible after the injury, could make major neurological deterioration before admission to a specialised spinal injuries unit a rare event.}

Key words: Spinal injuries; Neurological deterioration and its prevention; Prehospital care.

Spinal cord clinicians who are involved in the acute and ongoing care of people with spinal cord injuries have always been concerned about the possibility of patients sustaining further neurological deterioration after the accident before they arrive at a spinal cord injury unit. To date, no detailed work has been carried out to define the extent of this problem. This paper attempts to define the extent of the problem for the Victorian Spinal Injuries Unit Austin Hospital, Australia - a Spinal Injuries Unit which provides acute and ongoing spinal cord care for an urban and rural community of over 5 million people.

\section{Patients and methods}

All patients who sustained significant spinal cord injuries in Victoria or within 25 kilometres of the Victorian border, who were admitted to the Victorian Spinal Injuries Unit, Austin Hospital during the study period (1st March 1983 to the 28th December 1984) were included in the study. (Patients with hysterical 
spinal cord paralysis and patients who were discharged within 72 hours of their admission to the Unit were excluded). Data was collected by an interview with patient, witnesses of accident, ambulance personnel involved in the initial treatment of the patient and medical practitioners involved in patients treatment pre-admission to the Spinal Injuries Unit. An assessment was made of the accident site and any material involved in the accident. The patient's admission records at the Victorian Spinal Injuries Unit, Austin Hospital were assessed. Radiological investigations performed pre-admission outside the Spinal Injuries Unit and on admission to the Spinal Injuries Unit were also assessed. All data was collected and recorded by the author.

All information was collected within 7 days of the patient's admission to the unit. The author travelled over 60000 kilometres by motor vehicle during the study period to collect the necessary data.

\section{Results}

One hundred and twenty-four patients satisfied the study criteria during the study period. Only one patient refused to participate in the study. Seventy per cent (80) of patients studied were admitted to the Unit within 12 hours of their injury.

\section{Neurological deterioration}

Neurological deterioration in spinal cord injury is difficult to analyse, for two reasons:

(a) Possibility of observer error.

(b) If neurological deterioration has occurred, it can be difficult to ascertain how much deterioration was due to the 'natural disease process' and how much deterioration was due to inappropriate handling.

In this study the Frankel classification (Frankel et al., 1969) was used to ascertain the patient's neurological status at four distinct locations: accident site before seen by ambulance officers, initial ambulance officer's assessment, local hospital assessment and assessment at the Victorian Spinal Injuries Unit, Austin Hospital.

The neurological change patients sustained between the time of injury and the time they were admitted to the Victorian Spinal Unit, Austin Hospital have been presented in Table I. Twenty-six per cent of patients sustained major neurological deterioration between the time they were injured and the time they were admitted to the Spinal Unit. Table II shows the degree of major neurological deterioration which occurred from the time the patient was injured to the time the patient was admitted to the Spinal Injuries Unit.

The site at which major neurological deterioration occurred has been presented in Table III. Of the 9 cases who sustained major neurological deterioration during the initial ambulance assessment and ambulance transport to the local hospital, spinal injuries were not suspected by the ambulance officers involved in 8 cases. When the diagnosis was not suspected, the injured part was not immobilised, and the patient was not lifted so as to prevent vertebral movement. In one case where the diagnosis was suspected, the patient's neck was not immobilised as the injury was suspected to be at the thoracic, not the cervical 
Table I Neurological status of patient between time of injury and time of admission to spinal injuries unit

\begin{tabular}{lcc}
\hline \multicolumn{1}{c}{ Patients neurological status } & Numbers & ${ }^{\circ}{ }_{\mathrm{o}}$ \\
\hline Complete paralysis & 29 & 23.6 \\
Incomplete paralysis stable & 14 & 11.4 \\
Improvement in neurology & 26 & 21.1 \\
Minor neurological deterioration & 22 & 17.9 \\
Major neurological deterioration & 32 & 26.0 \\
Total & 123 & \\
\hline
\end{tabular}

Table II Degree of major neurological deterioration (change in Frankel classification between time of injury and time admitted to spinal unit)

\begin{tabular}{|c|c|c|c|c|c|}
\hline $\mathrm{AB}$ & $\mathrm{AB}$ & & $\mathrm{AC}$ & $\mathrm{AD}$ & $\mathrm{AE}$ \\
\hline 0 & 0 & & 0 & 0 & 0 \\
\hline BA & $\mathrm{BB}$ & & BC & $\mathrm{BD}$ & $\mathrm{BE}$ \\
\hline 0 & 0 & & 0 & 0 & 0 \\
\hline CA & CB & & $\mathrm{CC}$ & $\mathrm{CD}$ & $\mathrm{CE}$ \\
\hline 0 & 0 & & 0 & 0 & 0 \\
\hline $\mathrm{DA}$ & DB & & $\mathrm{DC}$ & $\mathrm{DD}$ & $\mathrm{DE}$ \\
\hline 3 & 7 & 1 & 10 & 0 & 0 \\
\hline EA & $\mathrm{EB}$ & & $\mathrm{EC}$ & $\mathrm{ED}$ & $\mathrm{EE}$ \\
\hline 5 & 3 & & 4 & 0 & 0 \\
\hline
\end{tabular}

In each square of the grid are two letters of the alphabet, the first related to the neurological lesion after injury but before neurological deterioration and the second to the patient's neurological lesion on admission to the Victorian Spinal Injury Unit, Austin Hospital.

Table III Site of major neurological deterioration

\begin{tabular}{lcc}
\hline \multicolumn{1}{c}{ Site } & Numbers & $0_{0}$ \\
\hline $\begin{array}{l}\text { Accident site } \\
\text { Initial ambulance assessment and }\end{array}$ & 3 & 9.4 \\
$\quad$ ambulance transport to local hospital & 9 & 28.1 \\
$\begin{array}{l}\text { Local hospital } \\
\text { Ambulance transport from local }\end{array} \quad 17$ & 53.1 \\
$\quad$ hospital to the Spinal Unit & 2 & 6.3 \\
Other & 1 & 3.1 \\
\hline
\end{tabular}

level. Of the 17 cases in which major neurological deterioration occurred at the local hospital, the diagnosis was not suspected in 14 cases. Major neurological deterioration occurred after surgery for a traumatic tear of the arch of the aorta in 2 of these cases. In the remaining 12 cases, the injured part was not immobilised and the patient was not lifted so as to prevent vertebral movement. Major neurological deterioration occurred due to inadequate immobilisation and inappropriate handling in the three cases in which the diagnosis was suspected.

Table IV compares the neurological level of all the patients in the study and the numbers which deteriorated in each group. Major neurological deterioration is not correlated with any neurological level. Table $\mathrm{V}$ compares the cause of 
Table IV Neurological level of patients who sustained major neurological deterioration before admission to the Spinal Unit

\begin{tabular}{ccc}
\hline Neurological level & Major neurological deterioration & Total patients \\
\hline Cervical & $18\left(26.5^{\circ}{ }_{0}\right)$ & $68\left(55.3^{\circ}{ }_{0}\right)$ \\
Thoracic & $8\left(22.2^{\circ}{ }_{0}\right)$ & $37\left(30.1^{\circ}{ }_{0}\right)$ \\
Lumbar & $6\left(40.0^{\circ}{ }_{0}\right)$ & $15\left(12.2^{\circ}{ }_{0}\right)$ \\
Sacral & $0\left(0^{\circ}{ }_{0}\right)$ & $3\left(2.4^{\circ}{ }_{0}\right)$ \\
\hline
\end{tabular}

Table V Major neurological deterioration by cause of injury

\begin{tabular}{lcc}
\hline \multicolumn{1}{c}{ Cause of injury } & $\begin{array}{c}\text { Major neurological deterioration } \\
\text { by cause of injury }\end{array}$ & Total patients \\
\hline Motor car accidents & 11 & 41 \\
Motor bike accidents & 7 & 24 \\
Pedestrian & 2 & 3 \\
Bicycle & 0 & 3 \\
Falls & 8 & 26 \\
Diving & 0 & 8 \\
Horse riding & 2 & 7 \\
Australian rules & 1 & 4 \\
Assault & 0 & 2 \\
Falling weights & 0 & 2 \\
Others & 1 & 3 \\
\hline
\end{tabular}

Table VI Major neurological deterioration by time of diagnosis of spinal injury

\begin{tabular}{lcc}
\hline Time of preliminary diagnosis & $\begin{array}{c}\text { Number diagnosed } \\
\left.\text { and }{ }^{\circ} \text { of all patients }\right)\end{array}$ & $\begin{array}{c}\text { Major neurological deterioration } \\
\left({ }^{\circ} \text { of each category }\right)\end{array}$ \\
\hline Ambulance officers & $80\left(65.0^{\circ}{ }_{0}\right)$ & $11\left(13.8^{\circ}{ }_{0}\right)$ \\
Accidentandemergency department & $23\left(18.7^{\circ}{ }_{0}\right)$ & $9\left(39.1^{\circ}{ }_{0}\right)$ \\
After admission to local hospital & $20\left(16.3^{\circ}{ }_{0}\right)$ & $12\left(60.0^{\circ}{ }_{0}\right)$ \\
\hline
\end{tabular}

injury of all patients and the numbers which deteriorated in each group. Major neurological deterioration is not correlated with any particular cause of injury. Table VI relates the number who deteriorated to the time the initial preliminary diagnosis of spinal cord injury was suspected. The longer it takes treating staff to suspect a diagnosis of spinal cord injury, the greater is the possibility of major neurological deterioration occurring in that patient. The greater the number of treating staff who handle a patient before a diagnosis of spinal cord injury is suspected, the greater is the possibility of major neurological deterioration occurring in that patient.

Two cases occurred following surgery for a traumatic tear of the arch of the aorta. Both patients had normal neurological function pre-surgery. Five cases occurred in patients who had sustained hyperextension injuries. In 2 cases, the patients were treated appropriately from the moment of impact. In hyperextension injuries, it is impossible to determine whether neurological deterioration is due to spinal cord oedema, a vascular problem, or inappropriate handling of the patient as the patient's neurological deterioration developed over a period of time. Major motor neurological deterioration in patients with skeletal fractures occurred in 25 cases. In six of the cases, the diagnosis was suspected when the deterioration occurred. In the other 19 patients the diagnosis had not been suspected when neurological deterioration occurred. Neurological deterioration 
Table VII Major neurological deterioration after diagnosis in patients with skeletal damage

\begin{tabular}{lc}
\hline \multicolumn{1}{c}{ Reasons for deterioration } & Numbers \\
\hline Inappropriate lifting of patients & 3 \\
Partial immobilisation of injured part & 1 \\
Injured part not immobilised & 2 \\
\hline
\end{tabular}

Table VIII Major neurological deterioration before diagnosis in patients with skeletal damage

\begin{tabular}{lc}
\hline \multicolumn{1}{c}{ Reasons for deterioration } & Numbers \\
\hline Inadequate transport of patient & 2 \\
Inappropriate lifting of patient & 6 \\
Inadequate immobilisation of injured part & 3 \\
No immobilisation of injured part & 7 \\
Inappropriate movement by patient & 1 \\
\hline
\end{tabular}

in these cases was most likely due to mishandling as the patients neurological deterioration was sudden and was related to inappropriate management of the patient.

Table VII outlines why patients with skeletal damage sustained major neurological deterioration even though diagnosis of spinal column or cord damage had been suspected. Neurological deterioration may have been averted in the 6 cases in which the diagnosis had been suspected had appropriate treatment been instituted before the patient was admitted to the Unit. Table VIII outlines why 19 cases with skeletal damage developed neurological deterioration due to inappropriate handling and immobilisation before anyone suspected the possibility of a spinal cord injury. In these cases neurological deterioration may have been prevented if a diagnosis of vertebral column or partial cord damage had been suspected.

\section{Discussion}

Nursing and medical staff are not recognising spinal cord injuries in cases in which ambulance officers have not suspected the diagnosis. This suggests that if an ambulance officer suspects a diagnosis of spinal cord injury and makes this point clearly at the accident and emergency handover to nursing or medical staff, major neurological deterioration could be a rare event. The key to the prevention of major neurological deterioration in patients who have only vertebral column damage or partial neurological dysfunction is a theoretical and practical understanding of the spinal column and cord. Suspicion of the possibility of spinal cord injury followed by appropriate handling and immobilisation of these patients by treating 'staff' as soon as possible after the injury could make major neurological deterioration a rare event.

A dramatic reduction in the number of patients who sustain major neurological deterioration between the time they are injured and the time they are admitted to a spinal injuries unit could be achieved by the development of specific, ongoing, comprehensive awareness programmes tailored for ambulance officers, accident and emergency staff, local medical practitioners, and the 


\section{THE SPINEX CARD}

\section{SPINAL CORD INJURY CARD}

THE LEVEL AT WHICH SENSATION IS ALTERED OR ABSENT IS THE LEVEL OF INJURY

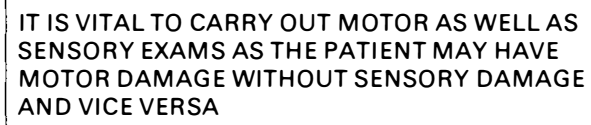

\section{SENSORY EXAMINATION}

1 EXAMINE BY:

A. Light touch

B. Response to pain.

2 USE:

The forehead as your guide to what is normal sensation.

3 EXAMINE:

A. Upper limbs and hands.

B. Lower limbs and feet.

4 EXAMINE; Both sides.

5 T.4 EXAMINATION: Must be carried out in the MID-AXILLARY lines, NOT the MIDCLAVICULAR line, as C2, C3 and C4 all supply sensation to the nipple line

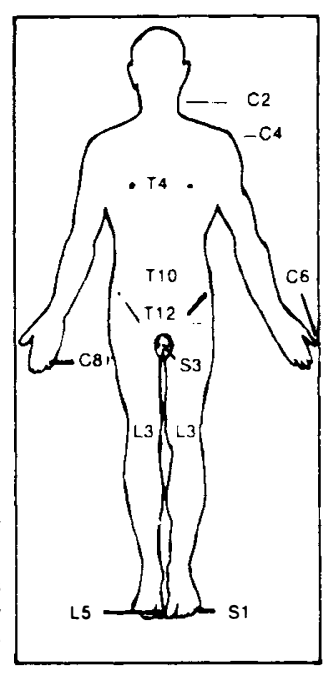

IT IS IMPORTANT TO CARRY OUT ALL OF THE ABOVE AS A VARIETY OF SENSORY CHANGES MAY OCCUR

Sponsored by: COBURG LIONS \& A.S.M.

Supplied by: BROADMEADOWS BRANCH A.S.M Thanks to: DrJ. TOSCANO

\section{MOTOR EXAMINATION}

THE LEVEL AT WHICH WEAKNESS OR
ABSENT MOVEMENT IS NOTED IS THE
LEVEL OF INJURY

\begin{tabular}{|c|c|}
\hline MOTOR EXAMINATION & :EXAMINE BOTH SIDES \\
\hline $\begin{array}{c}\text { UPPER LIMB MOTOR } \\
\text { EXAM }\end{array}$ & $\begin{array}{c}\text { LOWER LIMB MOTOR } \\
\text { EXAM }\end{array}$ \\
\hline ASK PATIENT TO: & ASK PATIENT TO: \\
\hline $\begin{array}{ll}\text { A Shrug Shoulders } & =\mathrm{C} 4 \\
\mathrm{~B} \text { Bend the Elbow } & =\mathrm{C} 5 \\
\mathrm{C} \text { Push Wrist back } & =\mathrm{C} 6 \\
\mathrm{D} \text { Open/Close Hands } & =\mathrm{C} 8\end{array}$ & $\begin{array}{lr}\text { A Flex Hip }=\mathrm{L} 1 & \& \mathrm{~L} 2 \\
\text { B Extend Knee } & =\mathrm{L} 3 \\
\text { C Pull Foot up } & =\mathrm{L} 4 \\
\text { D Push Foot down } & \\
& =\mathrm{L} 5\end{array}$ \\
\hline
\end{tabular}

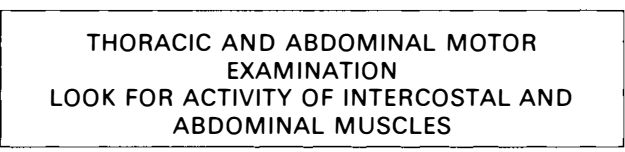

\begin{tabular}{|c|c|}
\hline \multicolumn{2}{|c|}{$\begin{array}{l}\text { DIAGNOSIS OF SPINAL CORD INJURY } \\
\text { IN THE UNCONSCIOUS PATIENT }\end{array}$} \\
\hline $\begin{array}{l}\text { A Look for paradoxical } \\
\text { respiration (a Quad has } \\
\text { lost intercostal muscles } \\
\text { so he relies on the } \\
\text { diaphragm to breathe). } \\
\text { B Flaccid limbs. } \\
\text { C Loss of response to } \\
\text { painful stimuli below } \\
\text { the level of the lesion. }\end{array}$ & $\begin{array}{l}\text { D Loss of reflexes below } \\
\text { level of lesion. } \\
\text { E Erection in the } \\
\text { unconscious male. } \\
\text { F Low B.P. (systolic Less } \\
\text { than 100) associated } \\
\text { with a normal pulse or } \\
\text { bradycardia indicates } \\
\text { Pt. may be QUADRI- } \\
\text { PLEGIC. }\end{array}$ \\
\hline
\end{tabular}

\section{TREATMENT:}

$$
\begin{aligned}
& 1 \text { A.B.C. } \\
& 2 \text { Immobilise injured part. } \\
& 3 \text { Lift Pt. in one piece in position found. } \\
& 4 \text { Don't move patient too many times. }
\end{aligned}
$$

Figure I Emergency spinal card - The Spinex Card.

general public. These programmes would identify at risk situations, acquaint treating staff with a method of examining patients with vertebral column or cord damage, stress the importance of appropriate lifting and immobilisation techniques. Figure 1 shows an emergency spinal card which is carried by most Victorian Ambulance Officers and by many Australian Ambulance Officers. The Spinex card was produced as a direct consequence of this study. Rank and file members of the Broadmeadows branch of the Ambulance Service Melbourne 


\section{ST. JOHN AMBULANCE BRIGADE SPINAL INJURY CARD}

\section{THE SPINE}

The spine consists of two distinct parts:

A THE SPINAL COLUMN

B THE SPINAL CORD

A The Spinal Column consists of bones, discs, ligaments and muscles. It:

i) Keeps us erect

ii) Protects the spinal cord.

B The Spinal Cord is a soft structure which runs inside the spinal column. It:

i) Transmits messages from the brain to the body

ii) Transmits messages from the body to the brain.

\section{SPINAL INJURY}

A Spinal Injury occurs when:

i) The spinal column is damaged or

ii) The spinal cord is damaged or

iii) Both the spinal column and cord are damaged.

\section{SPINAL COLUMN DAMAGE}

Damage to the spinal column presents as pain at the injured site.

\section{SPINAL CORD DAMAGE}

I) COMPLETE division of the spinal cord stops messages travelling up and down the cord and presents as a complete loss of power and feeling below the level which is divided.

II) INCOMPLETE division of the spinal cord presents as:

i) Diminished feeling

or

ii) Pins and needles and burning feelings or

iii) Diminished power or

iv) All of the above below the level of partial damage.

DAMAGE TO THE SPINAL CORD CAUSES PERMANENT PARALYSIS
SUSPECT THE DIAGNOSIS

DIAGNOSIS AND TREATMENT OF SPINAL

INJURY IN THE CONSCIOUS TRAUMA

PATIENT

\section{DIAGNOSIS}

Trauma patients who complain of:

1 Painful spine

or

2 Pins and needles in arms, legs or body

or

3 Weakness in arms or legs

or

4 Absent movement in arms or legs

or

5 All or some of the above should be treated as spinal patients.

\section{TREATMENT}

1 Ask the patient NOT TO MOVE.

2 LEAVE THE PATIENT IN THE POSITION YOU FIND HIM/HER until ambulance assistance arrives.

3 If you MUST move the patient (e.g. fire, risk of further accident, etc.) MOVE THE PATIENT 'IN ONE PIECE' - do NOT twist or bend the injured part.

DIAGNOSIS AND TREATMENT OF SPINAL INJURY IN THE UNCONSCIOUS PATIENT

\section{DIAGNOSIS}

1 If a person is found unconscious after an accident, they may have injured their spinal column or cord or both their spinal column and cord.

\section{TREATMENT}

1 The unconscious patient MUST be placed in the coma position.

2 Once the patient has been placed in the coma position do not move the spine unless necessary.

3 Resuscitation (Airway, Breathing, Circulation) ALWAYS takes precedence over Spinal First Aid).

IF YOU DON'T THINK ABOUT THE POSSIBILITY OF A SPINAL INJURY YOU WILL MISS IT!!!

Dr. J. Toscano

(Provisional Card only - for Clinical Trial)

Figure 2 Provisional spinal card undergoing clinical trials. 
initiated and helped in the design and production of the Spinex card. The production of the Spinex card for Ambulance Officers sparked a request from the Victorian Branch of the St John Ambulance Brigade for a spinal injury card for their members and trained first aiders. Figure 2 shows a provisional spinal card which is undergoing clinical trials at present.

\section{Conclusion}

Today in 1987, the greatest challenge facing spinal injury units is the establishment of an independent prevention unit within each spinal cord injury unit. This prevention unit would be responsible for conducting ongoing research on primary and secondary risk factors in trauma-induced spinal cord dysfunction and would be responsible for establishing prevention programmes, liaising with various government departments and private agencies, and would be responsible for ongoing education of the general public, paramedical, nursing staff and medical practitioners about traumatic spinal cord paralysis.

Primary risk factors are those factors which predispose an individual to develop traumatic spinal cord paralysis. Secondary risk factors are those factors which determine prognosis from the time of injury to the time the patient is admitted to the emergency room of a spinal cord injury unit.

\section{References}

Frankel HC, HaNCOCK DO, HysLop G, et al. 1969 The value of postural reduction in the initial management of closed injuries of the spine with paraplegia and tetraplegia. Paraplegia 7: 179192. 